\title{
Transformações e Desafios da Atenção Privada em Saúde no Brasil nos Anos 90
}

\author{
MARIA DE FÁTIMA SILIANSKY DE ANDREAZZI \\ GEORGE EDWARD MACHADO KORNIS
}

\section{RESUMO}

Este texto procura extrair, da heterogeneidade apresentada pelo setor privado em saúde, no Brasil, o dado qualitativamente novo dos anos 90, bem como os desafios da nova dinâmica desse setor, especialmente em sua relação com o Estado. Apresenta uma introdução, apontando elementos considerados essenciais para a compreensão das mudanças ocorridas no setor saúde. Nessa perspectiva, localiza as mudanças no quadro de referência do modelo econômico adotado pelo país, nos anos 90, com foco nos desenvolvimentos vinculados aos ditames da globalização produtiva e, sobretudo, financeira. Em seguida, na segunda e terceira seções, são apresentadas as principais mudanças no interior do setor privado em saúde, quanto a demanda, oferta e suas inter-relações. Finalmente, à guisa de epílogo, são apresentados alguns dos desafios interpostos na relação entre os provedores e os consumidores de atenção à saúde, dita suplementar, ou a assistência à saúde "hors-SUS".

Palavras-chave: Brasil; reforma sanitária - 1990-1999; atenção privada em saúde; seguro privado de saúde; relações público-privadas em saúde. 


\section{Introdução}

O presente artigo deriva da tese intitulada Teias e tramas: relações público-privadas no setor saúde brasileiro na década de 90 (Andreazzi, $2002)^{3}$, que se propôs a delinear as transformações do setor privado de saúde no Brasil, em especial, suas relações com a política pública de saúde. $\mathrm{O}$ quadro de referência do trabalho localiza-se no modelo econômico adotado pelo país, nos anos 90, com foco nos desenvolvimentos vinculados aos ditames da globalização produtiva e, sobretudo, financeira. O artigo apóia-se, fundamentalmente, no último capítulo da tese, no qual se procura extrair, da heterogeneidade apresentada pelo setor privado em saúde, o dado qualitativamente novo e os desafios da nova dinâmica do setor privado, em sua relação com o Estado.

No Brasil, sobretudo nas últimas duas décadas, a existência de mercados privados de saúde já estava consolidada, tanto para o financiamento quanto para a prestação efetiva de serviços. O principal elemento propulsor da dinâmica dos prestadores privados de serviços de saúde, ao menos no período 1950-80 (Mesa-Lago, 1989), foi o seguro social, em sua opção preferencial por terceirizar, em vez de prestar diretamente atenção à saúde. Vale observar que outros elementos propulsores, embora menos importantes no volume de transações e na visibilidade social, já estão presentes ao longo dessas três décadas. Dentre eles, a presença de um mercado de desembolso direto para serviços privados de saúde. Trabalhos pioneiros também apontaram, a partir dos anos 80, para o desenvolvimento de um mercado de planos de seguros privados de saúde, paralelo à própria terceirização do seguro social, que era processado através das empresas médicas de prépagamento (Cordeiro, 1984; Médici, 1990; Andreazzi, 1991).

$\mathrm{Na}$ recente literatura brasileira sobre o tema da privatização em saúde, o foco esteve localizado nos problemas existentes na relação entre seguro social (o qual, posteriormente, torna-se o Sistema Único de Saúde) e prestadores privados de serviços de saúde 4 . Trabalhos latino-americanos dos anos 90 (Laurell, 1995; Dias, 1995) já privilegiaram o tratamento hierarquizado do setor privado, procurando identificar as características de cada segmento. Entendeu-se, aqui, que o eixo que permitiria a identificação mais precisa da estratificação social existente no setor privado em saúde e seus respectivos interesses materiais e formas de organização, assim como dos correspondentes posicionamentos de seus distintos agentes, em face das políticas públicas, seria o processo de acumulação de capital. 
No final dos anos 80, paralelamente a um crescimento da demanda por atenção privada da saúde intermediada por seguros, o setor privado em saúde, no Brasil, já era caracterizado por grande heterogeneidade dos agentes econômicos, quanto às formas jurídicas, institucionais e de densidade de capital. A entrada de companhias seguradoras no mercado, no final dos anos 70, mesmo que de forma ainda restrita, já sinalizava o interesse do grande capital financeiro na atenção privada à saúde, como previu Cordeiro (1984).

Transformações de monta ocorrem no Brasil a partir de meados dos anos 80. Defasadas em uma década com relação às reformas que ocorriam na maior parte do mundo desenvolvido e mesmo em alguns países em desenvolvimento, nos anos 90 são implementadas políticas de ajuste monetário e fiscal, de acordo com o receituário das agências financeiras internacionais (Sola, 1993). Esses ajustes foram considerados, pelo governo brasileiro, indispensáveis para a manutenção de superávits fiscais a serem carreados ao pagamento da dívida pública. A conseqüência de tal política foi a redução de recursos orçamentários para investimento e custeio - o que foi agudo, para o orçamento da saúde, especialmente no período entre 1990 e 1994 (Piola e Biasoto, 2001; Piola, Ribeiro e Ocké, 2000)5. Associadas a isso, ocorreram a liberalização do mercado interno e as reformas do Estado, que impulsionaram a privatização em muitos campos: direta, pela venda de segmentos produtivos estatais; ou indireta, pelo estímulo ao crescimento de agentes privados em setores, antes majoritariamente públicos.

$\mathrm{O}$ que a literatura especializada tem analisado sob a denominação de globalização, tendência à internacionalização comercial, financeira e do próprio processo de produção (Batista Jr., 1997; Tavares e Fiori, 1998) tem sido acompanhado por mudanças nas concepções anteriores acerca do papel do Estado e das políticas públicas, inclusive de saúde. Não seria a globalização um fenômeno novo, porém, amplificado pelas possibilidades tecnológicas atuais nas áreas de informática e telecomunicações (Hirst e Thompson, 1998).

Exposição detalhada acerca das conseqüências da globalização sobre as políticas de saúde pode ser vista em Rocha (1997). Uma síntese das principais tendências será aqui assinalada. Inicialmente, destacam-se as restrições à autonomia dos Estados nacionais em questões financeiras, monetárias e fiscais (Lerda, 1996). Para os regimes de previdência social, isto se traduziu na redução das contribuições compulsórias e para o fisco, na redução da disponibilidade geral de recursos orçamentários. Os impactos da globalização financeira sobre as finanças públicas seriam no sentido de 
transformá-las em reféns ${ }^{6}$ (Mello, 1998). A possibilidade de estabilidade monetária, via ajuste fiscal, para os países devedores, seria bastante reduzida pelo papel desregulamentador da nação hegemônica, os Estados Unidos, em sua capacidade de definir taxas de juros (Fiori, 1996; Teixeira, 1994). Portanto, estaria imposta à sociedade constante necessidade de reformas fiscais, seja para contenção dos gastos, seja para o aumento de impostos, com óbvias repercussões negativas sobre os serviços públicos. Trata-se, em última análise, da flexibilização dos serviços do Estado, adaptando-os aos orçamentos incertos e privatização, para retornar seu financiamento às próprias pessoas.

Os impactos microeconômicos da globalização sobre o setor produtivo também trazem implicações para as políticas de emprego e previdência (Kornis, 1998). Além da tendência de redução do emprego, decorrente dos processos de reestruturação produtiva, mediados pela disseminação de novas tecnologias de automação, existe o que Braga (1998) denomina de financeirização global. Esta tendência dos ganhos em mercados financeiros globais serem predominantes sobre os decorrentes de atividades produtivas (produção e comércio) acabou gerando um desvio de recursos, a serem investidos na produção, para a especulação. A financeirização tem conferido um dinamismo mínimo à renda nacional e à acumulação de capital produtivo. As instituições dominantes desta nova fase de acumulação predominantemente financeira (Chesnais, 1998) não seriam mais os bancos, entendidos como núcleos da constituição do capital financeiro, na formulação clássica de Hilferding (1973) e, sim, os mercados financeiros e organizações financeiras não-bancárias (mutual funds e fundos de pensão), associados à financeirização dos grupos industriais (Chesnais, 1998).

No Brasil, os resultados das reformas dos anos 90 não têm sido comparáveis aos obtidos na Era Vargas. O crescimento do PIB nessa década foi medíocre, tendo ocorrido duas recessões, uma durante o Governo Collor, em 1992, e outra em 1998 (Mattoso, 1999). Segundo esse autor, e também Singer (1999), afora um breve período pós-implantação do Plano Real (1994), em que a queda da inflação e a importação maciça de produtos propiciaram melhor poder de compra da população mais pobre, foi uma década em que a renda ficou ainda mais concentrada. Além disso, caiu a renda relacionada ao trabalho e aumentaram o desemprego e o subemprego.

Nesse quadro, o trabalho remanescente tendeu à flexibilização, à alta rotatividade e à maior precariedade nos benefícios sociais. A taxa de desemprego aberto triplicou em dez anos, passando de 3,0\% da PEA, em 1989, 
para 9,6\%, em 1999. Por outro lado, contabilizaram-se déficits na balança comercial, pela substituição da produção interna por importações. A inflação se manteve, não em dois dígitos como antes de 1994, mas com um crescimento permanente dentro da escala de um dígito. Vale destacar que a inflação pós-94 (Plano Real), por não cursar com uma indexação a compensar as perdas inflacionárias, significou que essas perdas foram reais. A política de controle da inflação através do aumento da taxa de juros provocou o disparo das dívidas públicas, externa e interna, a patamares nunca vistos em décadas recentes, restringindo ainda mais as possibilidades de financiamento do Estado. O crescimento do produto ao longo da década $1,9 \%$ ao ano - foi o mais baixo de todo o século XX (Pochmann, 2001).

A liberalização comercial e a privatização de estatais produtivas também se fizeram acompanhar de uma mudança patrimonial importante: quebra de pequenas e médias empresas, fusões e aquisições (muitas delas com a participação de capitais internacionais) e desnacionalização de variados setores, inclusive o financeiro (Sola, 1993).

No redesenho do aparelho de Estado brasileiro, além das próprias privatizações de empresas produtivas, vão-se forjando novas instituições e formas de funcionamento, a partir de uma "hiperatividade decisória do Executivo Federal", através de Medidas Provisórias (Diniz, 1997). As principais mudanças no âmbito no aparelho de Estado em termos de seu impacto na área de saúde foram:

a) a descentralização da execução de políticas sociais, que significou para o sistema público de saúde a implementação da própria agenda do SUS, porém com descompromisso financeiro da União, que passava longe de sua proposta básica. E um decorrente aumento da participação das instâncias descentralizadas de poder no financiamento da saúde (Faveret et al., 2001). Essa descentralização tomou também a direção de organismos paragovernamentais sem fins lucrativos, as Organizações Sociais, destino de algumas instituições federais de saúde de maior porte e complexidade (Ribeiro, 2001);

b) a constituição de agências reguladoras voltadas ao controle indireto de mercados. Na área de saúde foram criadas duas: a Agência Nacional de Vigilância Sanitária (1997) e a Agência Nacional de Saúde Suplementar (ANS), em 1999. Estas novas instituições teriam como características:

1) a autonomia administrativa e financeira, relacionando-se com o Executivo através de contratos de gestão, para contrapor-se às 
críticas prévias do engessamento do aparelho de Estado;

2) o "insulamento burocrático" (Brasil/MARE, 1997) respaldou-se em modelos weberianos do tipo ideal de burocracia. Este se manifestaria na impossibilidade de demissão dos diretores da agência por motivos de mudança de governo, o que lhes propiciaria, pelo modelo, independência e racionalidade decisória e, ainda, maior impermeabilidade ao rent-seeking ${ }^{7}$. Mantendo a perspectiva do insulamento, períodos de quarentena, quando de mudanças de direção, quanto a cargos a serem assumidos em empresas antes reguladas;

3) o envolvimento do consumidor, através da acessibilidade da informação, o que poderia ser considerado ainda incipiente, dados todos os sigilos que envolvem as atividades de algumas agências, como é o caso da saúde suplementar. Estaria parcialmente contemplado no que toca à prestação de contas através de audiências públicas e a incorporação dirigida pela agência, de membros da sociedade civil envolvidos com o setor a regular ${ }^{8}$;

4) a preconizada accountability ${ }^{9}$, da qual ainda não se conhecem exemplos, mas que significaria o compromisso dos dirigentes das agências com o cumprimento dos programas estabelecidos com a administração central através de contratos de gestão, no nosso caso, com o Ministério da Saúde. Os dirigentes são passíveis de penalidades correspondentes ao seu não-cumprimento do acordado.

Também no caso da reforma do Estado brasileiro dos 90, não há uma sistematização mais integral de seus resultados. Valem algumas considerações para entendimento dos processos específicos da relação Estado/mercado, no setor saúde. Assim, Glade (1998) considera que a diversificação e proliferação do setor paraestatal têm sobrepujado a capacidade do Estado de monitorar e controlar suas operações. Também Pereira (1997) comenta os limites na implementação de reformas baseadas no neo-institucionalismo, ou seja, no desenho de mecanismos (incentivos) para que o agente Estado atue em nome do principal consumidor na regulação dos mercados e onde a prestação de contas tem papel importante. Os limites acima referidos seriam a frágil informação do principal, sua incapacidade de monitoramento dos políticos dentro dos esquemas da democracia formal e a manipulação da mídia sobre a informação.

No setor de seguros, nos aponta Leopoldi (1998), as mudanças que 
ocorrem no Brasil com a globalização e a reforma do Estado. Elas partem da reconfiguração do setor financeiro no mundo após 1973 e suas repercussões sobre as seguradoras: declínio do banco comercial tradicional e crescimento do mercado de títulos e valores, internacionalização, desregulamentação e fim da segmentação do mercado. Surgem entidades que ligam bancos, seguradoras e indústrias, organizadas em conglomerados: “(...) neste período a companhia seguradora passa a ser tratada antes de tudo como uma investidora, pois produz grandes volumes de provisões que tendem a ser aplicados em investimentos no mercado financeiro (...)" (Leopoldi, 1998, p. 242). Por outro lado, segundo a mesma autora, grandes corporações, como Ford, Mercedes-Benz e Coca-Cola criam suas próprias seguradoras.

Assim, diferentemente do período anterior, esperava-se que os constrangimentos impostos ao Estado a partir de suas estratégias de submissão aos ditames da nova conjuntura internacional amplificassem o papel de outro agente para a transformação do setor saúde. Partindo de um grande motor calcado no financiamento público, típico do quadro anterior, em direção a mecanismos que se dão no interior do próprio mercado, ou seja, processos de produção e troca que passariam a ser indispensáveis para o entendimento global do setor saúde e para a formulação de políticas públicas.

Não estaria, entretanto, inteiramente tecido e tramado um enredo completo. Não só a dinâmica do setor privado parece muito acelerada, quanto a mais intensa heterogeneidade do país, econômica e social e, ainda, do próprio setor saúde, clama por análises adequadas de situações muito diferenciadas.

\section{Modificações na Demanda para Atenção Privada de Saúde}

No Brasil, a demanda por atenção privada à saúde financiada de forma direta pelas famílias tinha, no início da década de 80, certa importância. Conforme estudo efetuado pela OPAS (apud Médici, 1989), as fontes privadas, em geral, representaram $37,6 \%$ do total de gastos com saúde, sendo que $25,66 \%$ eram de pessoas físicas e $5,07 \%$ tinham origem em sistemas patronais. No final dos anos 90, inverte-se a importância relativa de cada componente do gasto privado das famílias. A partir da Pesquisa de Orçamentos Familiares (POF) do IBGE, de 1987 e 1996 ${ }^{10}$, Ocké, Geiger e Andreazzi (2002) encontraram um aumento relativo e absoluto na participação dos gastos com "seguro-saúde", e uma diminuição daqueles com "ser- 
viços médico-hospitalares". Considerando que os dados acima não permitem afirmar que a redução absoluta e relativa dos gastos diretos com assistência médico-hospitalar das famílias, entre 1987 e 1996, tenha significado redução da demanda por esses serviços, acreditamos ser esta hipótese consistente. Esses movimentos refletiram uma mudança qualitativa da composição da cesta de consumo com saúde nesses anos.

Na década de 90, o crescimento da demanda de seguros e planos de saúde, segundo dados existentes até $1998^{11}$, revelou-se menor do que nos anos anteriores. Essa desaceleração não é convergente com a maior visibilidade alcançada por este produto, tanto nos meios acadêmicos e profissionais, quanto na mídia. Tal visibilidade, se por um lado fomenta o interesse governamental de regular o mercado, por outro amplifica, ainda mais, a exposição pública do produto. Um dos fatores limitantes que eram apontados, para precisar o desenvolvimento dessa demanda, foi a inexistência e pouca confiabilidade das fontes de informação (Bahia, 1999). No entanto, o Suplemento Saúde da PNAD/IBGE, de 1998 (IBGE, 2000a), primeira pesquisa de caráter populacional mais abrangente sobre o tema, não refutou, de forma significativa, as estimativas anteriores. Enquanto trabalhos oriundos de representantes do mercado projetaram uma quantidade de beneficiários de 41 milhões de pessoas para 1996 (Catta Preta, 1997), a PNAD de 1998 encontrou 38,7 milhões com, ao menos, um plano de saúde, quando se sabe da existência de pessoas com superposição de coberturas, ou seja, com mais de um plano.

Assim, tão ou mais importante do que nos anos 90, foi o crescimento dessa alternativa privada de financiamento de saúde nos anos 70 e 80 . O gráfico 1 reflete o crescimento do mercado de seguros e planos privados. 


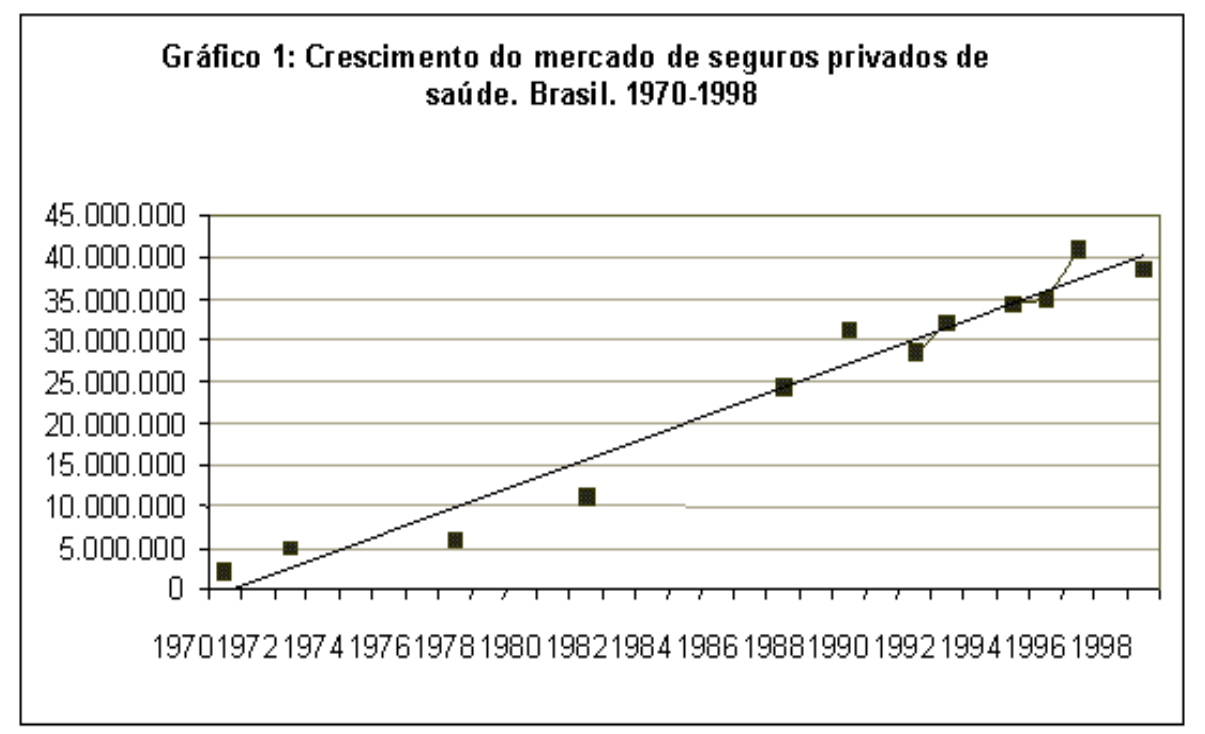

Agrupando-se os dados em diferentes períodos, de acordo com as políticas econômicas adotadas, numa periodização efetuada a partir de Teixeira $(1994)^{12}$, verifica-se, de modo mais claro, a estagnação dos anos 90 vis-àvis os anos 70/80 (quadro 1).

Quadro 1: Taxa de crescimento médio anual* dos usuários de seguros privados de saúde segundo conjunturas (em \%)

\begin{tabular}{ll|c}
\hline \multicolumn{2}{c|}{ Conjunturas } & \% \\
\hline Milagre e II PND & $1970-1978$ & 32,9 \\
Recessão Figueiredo & $1979-1983$ & 20.4 \\
Recuperação & $1984-1989$ & 15,1 \\
Recessão primeira metade 90 & $1990-1994$ & 2,2 \\
Estabilização (Real) & $1995-1998$ & 3.5 \\
\hline
\end{tabular}

Fontes: até 1989 - Andreazzi (1991); entre 1991 e 1994 - Mendes (1996); para 1995: Gazeta Mercantil (1996); para 1996 - Catta Preta (1997); para 1998: PNAD/IBGE (1998).

*Calculada a partir da seguinte fórmula:

$$
\operatorname{Taxa}=\frac{(\mathrm{yt}+\mathrm{n}-\mathrm{yn}) / \mathrm{yn}}{\mathrm{t}} \times 100
$$


Os dados da PNAD/1998 reafirmaram a centralidade das condições de reprodução material da vida, como a renda e o emprego, para a conformação do perfil da demanda por planos de saúde. Quanto à renda familiar, por exemplo, apenas $2,6 \%$ dos indivíduos situados na faixa menor que um salário-mínimo são cobertos, contra $76 \%$ nos de 20 ou mais salários-mínimos (IBGE, 2000).

Embora a principal fonte de financiamento dessa demanda, segundo ainda a PNAD/1998, seja o empregador (pois 62,2\% dos titulares de planos de saúde obtiveram através dele essa cobertura), dados esparsos dos anos 90 parecem indicar maior participação da renda dos indivíduos no pagamento dos prêmios. Isto pode ser percebido em São Paulo, através da Pesquisa de Condições de Vida (PCV) ${ }^{13}$. Observou-se que, ao longo dos anos 90, não houve diferenças significativas na cobertura de planos de saúde dos indivíduos, em torno de $44 \%$. Houve, sim, para os titulares, expressiva substituição da fonte pagadora que, da empresa empregadora e, em menor escala, do sindicato, passa ao próprio indivíduo. A participação relativa da empresa pagadora, desse modo, passa de 64,6\%, em 1994, para 45,9\%, em 1998. ${ }^{14}$ No Rio de Janeiro, inquérito populacional desenvolvido pela FIOCRUZ e FGV, no final dos anos 90, a partir de metodologia distinta da PCV, também verificou a centralidade da família como financiadora do gasto privado com saúde (Lobato, 2000). Embora o período de análise seja mais curto, dados da ABRAMGE também mostram certa tendência ao aumento dos clientes particulares no seu universo de beneficiários. Enquanto em 1997 esta participação foi de $25 \%$, em 2000 chegou a $28,7 \%$, representando a carteira que obteve ganhos absolutos de vidas, ao inverso da carteira empresarial, estagnada (www.abramge.com.br, com acesso em 2001).

Esses dados inequivocamente informam que o financiamento integral do empregador tem sido substituído por formas em que há participação financeira parcial ou total do indivíduo segurado, ainda que este conte com uma pessoa jurídica intermediando o contrato de seguro.

A desaceleração do crescimento da demanda privada por seguros, nos anos 90, não deve ter significado que os motores responsáveis por seu crescimento anterior tenham deixado de agir: o interesse pelo controle da mão-de-obra (Oliveira e Teixeira, 1978; Possas, 1989), a deterioração da oferta pública de serviços (Faveret e Oliveira,1989), o aumento de custos da atenção médica ${ }^{15}$. Outros fatores, entretanto, devem ter pesado mais nas decisões dos indivíduos e das empresas.

Para as empresas, os anos 90 confirmam, no país, as tendências estru- 
turais do capitalismo atual quanto à reestruturação produtiva poupadora de mão-de-obra, a demanda decrescente e crises periódicas de superprodução/ subconsumo, que têm imprimido a marca da mediocridade ao crescimento do produto interno (Pochmann, 2001; Mattoso, 1999). A dinâmica do emprego nos anos 90, em que imperou a precariedade, não tem beneficiado aqueles mais associados à cobertura de seguros privados e outras vantagens associadas à relação formal de trabalho, que, inclusive, contam com benefícios fiscais. As indústrias mais atingidas pela reestruturação produtiva foram aquelas em que a cobertura por planos privados de saúde, em 1998, era mais expressiva. Já quanto aos novos empregos, metade ocorreu em ramos de atividade em que a cobertura de planos de saúde é mais baixa (IBGE, 2000a).

O mercado individual de seguro depende, fundamentalmente, da renda. Esta tem sido intensamente comprometida na última década (Pochmann, 2001), não permitindo vislumbrar crescimento significativo da demanda de atenção privada à saúde, a partir dos gastos das famílias. Tudo isso se mantendo constante, os elementos da conjuntura apontam para um crescimento bastante restrito do mercado de seguros privados de saúde neste início de milênio.

Embora a apresentação mais detalhada dos dados possa ser encontrada na tese que serve de base para este artigo (Andreazzi, 2002), é importante assinalar, como exercício de aproximação, outra mudança significativa do financiamento da oferta de serviços privados de saúde. Esta se refere ao crescimento proporcionalmente maior das despesas com saúde efetuadas pelas diversas modalidades de seguros e planos privados de saúde do que daquelas referentes aos gastos públicos com assistência individual à saúde. Ao contrário, portanto, do período anterior, em que a dinâmica das políticas públicas era o motor principal que gerava transformações no mercado privado de serviços de saúde, nos anos 90 sua dependência de fontes privadas se intensificou.

\section{Mudanças na Oferta de Atenção Privada a Saúde no Brasil}

A estagnação da demanda por atenção privada à saúde, dentro da estrutura atual da economia brasileira, tende, para as firmas, a mudar o processo competitivo. Acirra-se a competição, que passa a ser pelas carteiras dos concorrentes e as fusões/aquisições, na medida em que a perspectiva de crescimento para as firmas individuais passa pela redução do mercado das 
concorrentes. Ao contrário da demanda, as taxas estimadas de crescimento dos prêmios de seguro saúde, nos anos 90 , não se reduziram em relação ao período anterior, como se pode verificar no quadro 2.

Quadro 2: Taxa de crescimento médio anual do faturamento de seguros privados de saúde segundo conjunturas (em\%)

\begin{tabular}{llc}
\hline \multicolumn{2}{c|}{ Conjunturas } & Valor \\
\hline Milagre e II PND & $1970-1978$ & Sem informação \\
Recessão Figueiredo & $1979-1983$ & Sem informação \\
Recuperação & $1984-1989$ & $15,7^{*}$ \\
Recessão primeira metade 90 & $1990-1994$ & 28,1 \\
Estabilização (Real) & $1995-1998$ & 37,0 \\
\hline
\end{tabular}

* estimada para todo o período a partir dos anos de 1987 e 1989.

Fontes: até 1989 - Andreazzi (1991); entre 1991 e 1994 - Mendes (1996); para 1995: Gazeta Mercantil (1996); para 1996 - Catta Preta (1997); para 1998: Mendes (2000), ajustado pelos dados do Ciefas e Abraspe (www.abraspe.org.br e www.ciefas.org.br).

$\mathrm{O}$ quadro 2 se baseou em dados apresentados na tabela 1. $\mathrm{O}$ aumento do faturamento por usuário, expresso em dólares, explica o crescimento da taxa de prêmios, a despeito da estagnação da demanda. Verifica-se sua artificial redução, em 1999, em função da maxidesvalorização da moeda americana.

Dos 80 para os 90 verifica-se, ainda, uma dinâmica distinta de crescimento entre as modalidades que compõem a oferta de planos e seguros privados de saúde. Na primeira metade da década de 90, em relação ao final dos 80 , há aumento da participação das seguradoras no mercado e redução da medicina de grupo. A autogestão e cooperativas, a despeito da redução apresentada em alguns anos da série, se apresentam mais estabilizadas quanto ao market-share do que a medicina de grupo, que vê cair, progressivamente, sua participação relativa no mercado. $\mathrm{O}$ crescimento das seguradoras não parece ter se dado por redução de preços, já que seu faturamento por usuário revelou-se, em geral, mais elevado do que as demais modalidades.

A crescente importância do seguro saúde para a acumulação das empresas seguradoras é constatada desde o final da década de 80 (Andreazzi, 


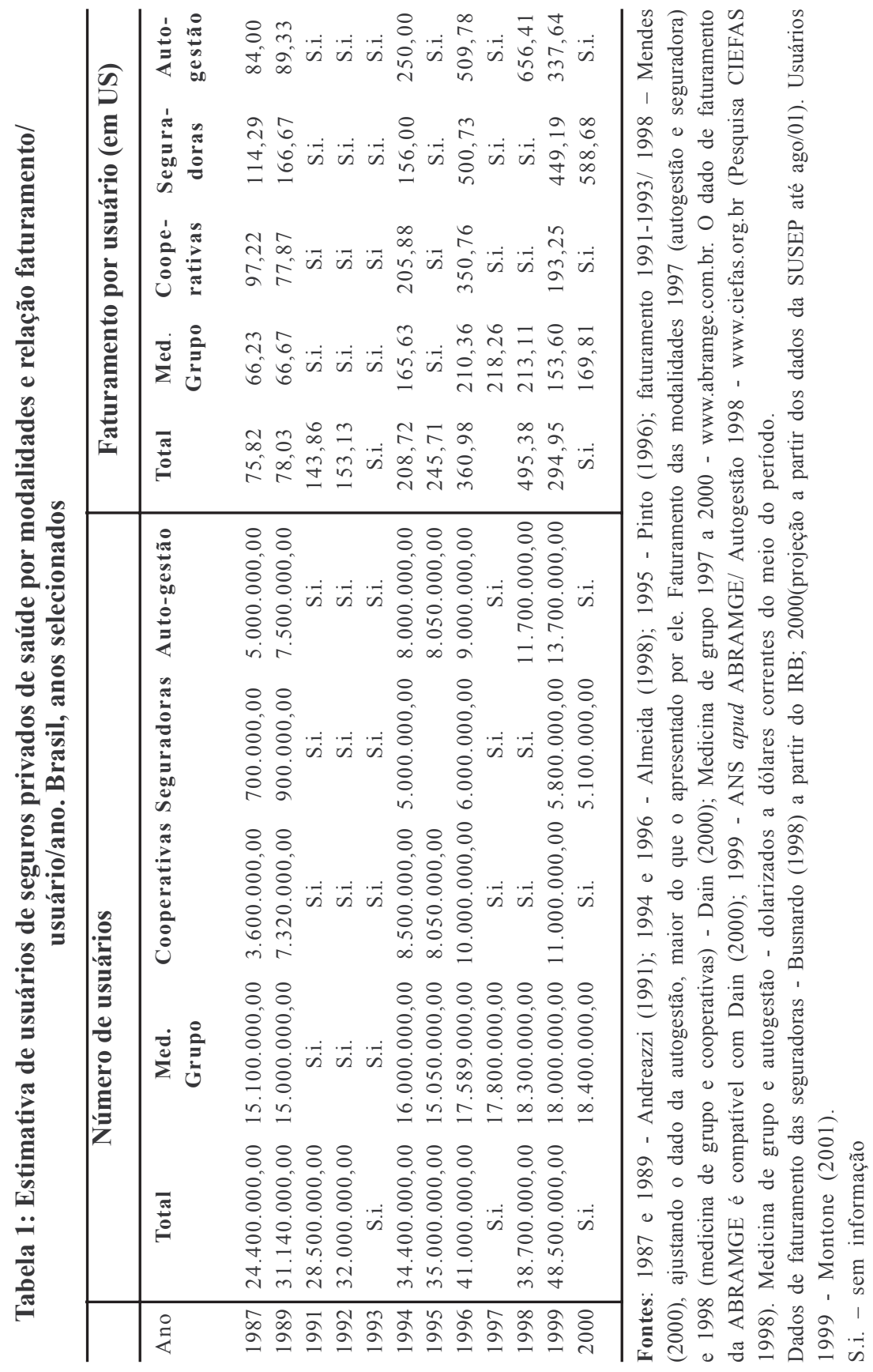

PHYSIS: Rev. Saúde Coletiva, Rio de Janeiro, 13(1):157-191, 2003 
1991). Em 1992, o seguro saúde já alcançava não a terceira, mas a segunda posição entre os ramos com maior arrecadação de prêmios (Gazeta Mercantil apud Lopes, 1993).

A lucratividade das firmas, ainda, é um tema colocado para a pesquisa no Brasil. O que se pôde perceber foi que a sinistralidade cresceu nesse período, colocando, para as empresas, a necessidade de contar com mecanismos de controle de sinistros bastante afinados. Tomando as seguradoras como exemplo, pela facilidade de acesso sistemático aos seus dados, vê-se que em 1986 a taxa de sinistralidade foi de 40,6\% (Andreazzi, 1991), enquanto que, em 1996, passou a 52,3\% (Gazeta Mercantil, 1996) ${ }^{16}$.

Numa conjuntura de crise econômica e estagnação de demanda, uma das principais estratégias das empresas foi a preferência por clientes corporativos em face aos individuais, pelos ganhos em escala e possibilidade de negociar preços bilateralmente, sem interferência da ANS, dentro do atual marco regulatório. Isso caracteriza um comportamento de aversão ao risco em face de conjuntura instável ${ }^{17}$.

Acreditamos que as empresas de autogestão e as seguradoras tenham mais possibilidades de manter-se no mercado do que as organizações médicas de pré-pagamento - cooperativas médicas e empresas de medicina de grupo. Estas apresentariam desvantagem maior no processo competitivo, não estando descartada, para as pequenas empresas, sua transformação em prestadoras de serviço para as grandes seguradoras e, mesmo, para algumas poucas grandes empresas de medicina de grupo de envergadura nacional. Tendo em vista que um dos determinantes mais importantes de concentração, na conjuntura da mundialização do capital, foi de ordem financeira, concentrar-se na intermediação financeira, centralizando a gerência de capitais a serem carreados para os processos de acumulação financeira e transferir o risco dos sinistros para instituições médicas, através de prépagamento, pode ser uma alternativa favorável para as seguradoras. A sobrevivência de algumas empresas médicas, constrangidas pela demanda decrescente, pode tornar vantajosa, por outro lado, a opção de funcionarem como firmas terceirizadas de um grupo financeiro. Quanto à autogestão, os processos de reestruturação produtiva, com a respectiva redução do emprego formal, podem ser um vetor de ajuste da fatia de beneficiários da massa por ela coberta. Custos fixos, numa conjuntura de demanda decrescente, sempre serão questionados, caso se disponha de alternativas de terceirização, o que vale para as estruturas administrativas próprias de planos de saúde das empresas. Entretanto, continuam válidos, tal como nos anos 80, os motivos 
mais relevantes que levaram as empresas produtivas a considerar seriamente essa opção: vantagens financeiras relativas à administração de fundos de dinheiro, redução de custos comerciais, em face às alternativas de compra de seguro no mercado.

A sobrevivência das cooperativas médicas e das instituições filantrópicas que organizaram planos próprios, num ambiente competitivo voltado à acumulação financeira e a padrões de competição liderados pelas empresas seguradoras, tem grande probabilidade de depender de um comportamento que aplaina as diferenças intrínsecas a essas modalidades. As cooperativas tinham como objetivo inicial a remuneração adequada do trabalho de seus numerosos médicos cooperados. Como firmas, portanto, seus processos de acumulação são imperfeitos - não têm objetivos lucrativos e apresentam mecanismos mais ampliados de decisão. Os hospitais filantrópicos devem passar pelos mesmos conflitos. No seu caso, a seleção de risco, necessária para se manterem competitivos e sobreviver face às empresas mercantis, particularmente as seguradoras, estabelece um conflito com sua missão de berço: a prestação de serviços comunitários. Isto inclusive lhes serve como possibilidade de investimentos para atualização da capacidade instalada, através de mecanismos da caridade privada, incompatíveis com a agressividade mercantil necessária para competir com as demais modalidades. Nos Estados Unidos, como resultado do ambiente competitivo desfavorável, a partir dos anos 80, muitos hospitais comunitários e universitários foram vendidos para empresas lucrativas (Salmon, 1995).

Para os serviços de saúde, observou-se que a década de 90, ao contrário das anteriores, foi um período de desaceleração do conjunto dos estabelecimentos de saúde, tanto públicos como privados. Uma pequena parcela dos hospitais privados foi, inclusive, fechada, entre 1992 e 1999, sendo as Pesquisas sobre Assistência Médico-Sanitária do IBGE (IBGE, 2000b). Mesmo os estabelecimentos privados que não chegaram a esse extremo parecem ter passado por uma reengenharia redutora de leitos, já que mais de $10 \%$ da capacidade instalada existente em 1992 foi desativada. Tal fato se deu, basicamente, no segmento lucrativo. Isto pode ser atribuído tanto à redução do financiamento público para seu custeio, através da contenção de repasses do SUS para compra de serviços, mas também a todo um movimento de desospitalização de doenças crônicas, tais como as psiquiátricas. Os ajustes no número de estabelecimentos, leitos e a redução das médias de permanência observadas também refletem mudanças nas técnicas de prestação de serviços hospitalares, seja de produto ou de processos. Tais mudanças têm 
sido incrementadas, mundialmente, pela busca de redução de custos com atenção médica por parte de instituições públicas e também pelos seguros saúde, sejam eles privados ou públicos. O processo competitivo entre os próprios hospitais se encarrega de disseminar e recriar os novos métodos de produção.

A manutenção de um crescimento da rede privada de cunho ambulatorial pode ter sido uma saída por algum tempo. De fato, o desvio da internação para o ambulatório é uma tendência encontrada em outros países (Ginzberg, 1996).

A segmentação da demanda, segundo suas fontes de financiamento, pode ser considerada uma das estratégias utilizadas pelos hospitais, ocorrendo, em geral, aumento da busca por convênios com seguros privados de saúde, redução de convênios com o SUS mais acentuada na Região Sudeste e uma redução do número de estabelecimentos com atendimento, apenas, particular. A maior parte dos hospitais privados ainda se mantém conveniada com o SUS, relação essa maior entre os não-lucrativos - filantrópicos e beneficentes (até para não perder benefícios fiscais) - do que nos lucrativos. Nos anos 90, parece ter ficado mais difícil, mesmo para alguns poucos hospitais privados, antes clientela exclusivamente direta, sobreviver sem crédito através de seguros saúde ${ }^{18}$. Há diferenças, porém, nessas estratégias, entre o segmento lucrativo e não-lucrativo, sintetizadas no quadro 3.

$\mathrm{Na}$ dependência do mercado, há distintas possibilidades de negociação por preços com as empresas de planos e seguros privados de saúde. Fruto das distintas possibilidades de relacionamento com os seguros privados, decresce a importância do SUS para a rede hospitalar privada, aumentando suas possibilidades de negociação com o setor público por uma complementação ${ }^{19}$.

As estratégias competitivas parecem estar levando o mercado a um processo de concentração, potencializado pela gravidade da conjuntura econômica recessiva. Isso pode ser observado na evolução da oferta de firmas seguradoras e de empresas de medicina de grupo. Quanto ao mercado do seguro saúde, observaram-se, desde o início de sua operação e, especialmente, na segunda metade dos anos 90, diversas entradas de empresas seguradoras, segundo dados da SUSEP (www.susep.gov.br). As empresas entrantes, no entanto, não lograram alcançar as firmas líderes já estabelecidas, que já eram grandes bancos ou seguradoras quando entraram no mercado de saúde, nos anos 80. Para as empresas de medicina de grupo, a despeito de seu grande crescimento numérico nos anos 80 e 90, a posição relativa das 
Quadro 3: Características de hospitais privados nos anos 90

\begin{tabular}{c|c}
\hline Lucrativos* & Não Lucrativos** \\
\hline $\begin{array}{c}\text { Menor participação do SUS como } \\
\text { fonte financiadora, em geral }\end{array}$ & $\begin{array}{c}\text { SUS está presente em mais de 90\% } \\
\text { dos estabelecimentos (exceções das } \\
\text { cooperativas e serviço social autôno- } \\
\text { mo, porém com pouco peso numérico) }\end{array}$ \\
\hline $\begin{array}{c}\text { Principal fonte - convênios com } \\
\text { planos de terceiros }\end{array}$ & $\begin{array}{c}\text { SUS associado a convênios com } \\
\text { planos de terceiros é a principal fonte } \\
\text { de financiamento }\end{array}$ \\
\hline $\begin{array}{c}\text { Maior participação relativa do } \\
\text { atendimento particular exclusivo }\end{array}$ & $\begin{array}{c}\text { Não há diferenças práticas quanto ao } \\
\text { plano próprio exclusivo. }\end{array}$ \\
\hline
\end{tabular}

Fonte: IBGE (2000).

* Foram assim classificadas as naturezas jurídicas existentes no questionário da AMS/IBGE de 1992 e 1998 - Empresa e economia mista.

** Foram assim classificadas as naturezas jurídicas existentes no questionário da AMS/ IBGE de 1992 e 1998 - Fundação, serviço social autônomo, entidade filantrópica, cooperativa, sindicato e beneficente.

principais firmas também não se alterou significativamente no período, segundo dados recentes da ABRAMGE (www.abramge.com.br).

Duas foram as principais dificuldades encontradas para medir o grau de concentração no mercado de seguros privados de saúde: a informação e a delimitação do mercado relevante para a avaliação da concentração. Em nível nacional, parecem competir grandes seguradoras e medicinas de grupo, além das cooperativas médicas, através de seus mecanismos de intercâmbio. O mercado parece aproximar-se mais de um modelo de oligopólio nãoconivente, não-organizado "(...) ocorrendo ações independentes das firmas, com menor exatidão com relação à reação das rivais e com guerras de preços ou de marketing (...)" (Kon, 1994, p. 33-4). Haveria, entretanto, desigualdade nos níveis de concentração, pois, considerando-se mercados regionais e locais, é possível que se encontre uma concentração maior do que no nível nacional.

No mercado de serviços de saúde, os movimentos de concentração verificados parecem se dar na direção da multiplanta, ou seja, das cadeias de estabelecimentos de saúde que podem, inclusive, fazer parte de conglo- 
merados que contem com um braço de intermediação financeira, seja ele carreado através de empresa seguradora ou empresa médica de pré-pagamento. Isso ocorre em função de características próprias dos serviços de proximidade, que englobariam a maior parte dos serviços de saúde dirigidos aos indivíduos e famílias. O tamanho dos mercados locais, territorialmente delimitados, limita o crescimento horizontal desses serviços. Sua expansão, particularmente em moldes capitalistas, requer a busca de outros mercados de proximidade, configurando redes de estabelecimentos interligadas que apresentam, inclusive, diversas vantagens competitivas em função da escala (Gadrey, 1996). Este tem sido, de fato, o padrão recente de concentração no mercado hospitalar, que tem ocorrido nas regiões de ponta do capitalismo brasileiro, observando-se, já, algumas redes de serviços de saúde, como a Rede Vita (Valor Econômico, 5/06/2001) e a Rede Labs/D'Or (Gazeta Mercantil, 15/03/2001).

Nas áreas que passaram por inovações técnicas de produtos e processos que permitiram uma revolução da produtividade do trabalho e mudanças nas relações sociais de produção (venda da força de trabalho), como foi o caso dos laboratórios de análises clínicas, o processo de centralização do capital, inclusive de penetração do capital internacional, tem sido notável (Gazeta Mercantil, 19/07/01). O modelo das empresas-rede (Chesnais, 1996) se adequa, bastante, no caso em pauta: empresas internacionais e grandes empresas nacionais que detêm marca e tecnologia, pequenos laboratórios que passam para a condição de franqueados ou terceirizados ${ }^{20}$.

A integração seguros/serviços, aproveitando-se de possibilidades de reduzir custos, que sempre constituiu uma faceta de modalidades, como a medicina de grupo, continuou a ser atraente para o conjunto das firmas, pois se percebeu aumento da capacidade instalada própria nessa modalidade (www.abramge.com.br). Na rede das cooperativas, muitos serviços próprios também têm sido construídos ${ }^{21}$. Isso apenas não é possível, nos marcos regulatórios atuais, para as seguradoras. Há que se notar, entretanto, a existência crescente de movimentos contrários, ou seja, de serviços de saúde, hospitais, por exemplo, criando firmas de seguro-saúde (Confederação das Misericórdias do Brasil, 1992; Cotta et al., 1998).

Quanto à internacionalização, entraram no mercado de seguro saúde privado, no Brasil, basicamente associações de grandes empresas multinacionais com firmas nacionais estabelecidas, em vez de entradas isoladas. Os casos mais marcantes envolveram seguradoras nacionais líderes do mercado e grandes conglomerados financeiros internacionais, ambos com 
presença significativa nos respectivos mercados nacionais de seguro saúde. Essas alianças pareceram ser uma estratégia competitiva para os dois lados, num modelo também parecido com o estudado por Chesnais (1996).

Para dirigentes do mercado (Sindicato das Seguradoras do RJ apud Gazeta do Rio, 13/07/01, p. A4), a explicação recai na vantagem competitiva das firmas nacionais, em termos do conhecimento do mercado nacional, não refutando as tendências observadas por Gadrey (1996) quanto à internacionalização do setor de serviços, em geral, em que fatores culturais têm maior importância, se comparada àquela verificada para a indústria. Uma certa subestimação desse processo por outros pesquisadores do tema (Bahia, 2001) parece se dar pela consideração não adequada das especificidades dos mercados de serviços, sobretudo os de proximidade, em que o conhecimento e fatores culturais têm recomendado a entrada de firmas internacionais em associação com as nacionais já presentes.

Detectou-se como mudança significativa nas tendências que apontam para o financiamento do investimento e o controle do capital no setor saúde, interesse do capital financeiro internacional, através de fundos institucionais de investimento, e nacional, através dos Fundos de Pensão ${ }^{22}$, através de mecanismos de securitização de dívida. Não há dados nacionais que permitam afirmar com mais consistência, mas esses fazem crer, assim como aponta Chesnais (1996), ser a saúde privada uma área de expansão do capital financeiro de nível mundial. Inclusive para garantir o escoamento da produção e a realização das mercadorias dos oligopólios industriais de bens de saúde, afetadas pelas crises de superprodução e a conseqüente demanda decrescente.

Tradicionalmente, há uma contradição entre os distintos prestadores, lucrativos, filantrópicos, universitários e o próprio setor público estadual e municipal, pelos recursos públicos federais destinados à saúde. Em alguns momentos das décadas passadas, ora uns, ora outros, foram mais privilegiados, na dependência da origem da burocracia dominante no aparelho de Estado e das pressões políticas. Houve épocas mais recentes em que, deliberadamente, se reforçou um dos privados visando a enfraquecer outros, como foi o caso das filantrópicas, na conjuntura de 1984 a 1989. No Brasil, a ideologia liberal do livre mercado na saúde sempre foi retórica, pois, com raras exceções, a autonomia financeira dos hospitais privados, relativa aos recursos públicos para custeio, inclusive investimento, além de não ocorrer homogeneamente é também mais recente.

Com o grande desenvolvimento do seguro privado, passa-se a ter outra 
contradição, derivada do movimento de constituição de capacidade instalada própria das empresas seguradoras, adquirindo hospitais, muitos em má situação financeira, o que caracterizou a década de 90.

A história dos embates entre o público e o privado, nesses anos, sobretudo até meados dos anos 90 , foi hegemonizada pela discussão da estatização progressiva dos estabelecimentos privados de saúde, bandeira reformista de transformações da VIII Conferência Nacional de Saúde (1986) - em contrapartida, pelo movimento de resistência desse segmento a ser estatizado. E, ainda, pela identificação do empresário hospitalar como o vilão da atenção à saúde no Brasil ${ }^{23}$. Contudo nota-se, recentemente, uma tendência de aproximação dos provedores privados, que são preferencialmente clientes do SUS, com os estatais, para defesa de recursos públicos mais amplos para a saúde ${ }^{24}$. Parte dessa inclinação pode ser devida à tomada de consciência da demanda limitada dos clientes privados, e ainda da competição desigual com os provedores mais diretamente relacionados às empresas de seguro.

A heterogeneidade política do setor privado segue pari-passu sua heterogeneidade econômica. Os intermediadores financeiros em geral principalmente aqueles que têm nessa atividade a sua razão precípua, ou seja, as seguradoras e as grandes empresas de medicina de grupo - sabem que seu desenvolvimento futuro passa pela redução do Estado para determinadas parcelas da população.

Os intermediadores financeiros constituídos para o controle da mão-deobra e diferenciações qualitativas de atenção à saúde, ou seja, as autogestões, tendo um padrão limitado de acumulação, não necessariamente disputam com uma seguridade social universal.

As cooperativas médicas, as pequenas e médias empresas de medicina de grupo e os hospitais filantrópicos podem ter contradições quanto à seguridade universal, por vislumbrar uma acumulação financeira. Porém, essas empresas podem ser convertidas à condição de prestadoras de serviços de saúde, desde que isto represente níveis aceitáveis de remuneração.

Assim, entende-se que os prestadores de serviços de saúde, quanto aos processos de desenvolvimento da política de saúde, estejam divididos em grandes linhas de análise, entre duas perspectivas, em função de sua inserção no mercado. A primeira pode fazer, desde que recompensada, uma aliança pró-políticas de reforço aos mecanismos públicos de seguridade social para o financiamento da atenção à saúde, seja pela sua dependência atual do SUS, seja pela potencial possibilidade de inserção como prestador de 
serviços de saúde. A outra perspectiva tende a reforçar os mecanismos de segmentação do financiamento, através de sistemas duais, pois lhe interessa, fundamentalmente, a acumulação financeira.

\section{Desafios para as Políticas Públicas}

A "assistência suplementar em saúde" foi uma denominação empregada pelo mercado para designar a parcela do setor privado de saúde que opera de modo exógeno às relações contratuais com o SUS. No Brasil dos anos 90, foram um dos principais focos da política nacional de saúde. Sua regulação foi apontada pelos organismos internacionais como uma das funções básicas do novo Estado reformado, que aí deveria concentrar sua intervenção, retirando-se, assim, do financiamento e da provisão de serviços (Banco Mundial, 1993). Os elementos que deveriam nortear a regulação nesse momento não estão suficientemente esclarecidos, a ponto de dotar o Estado e agentes envolvidos de informações necessárias para orientar uma ação coordenada (Almeida, 1998). Ilustra as dificuldades envolvidas nesse processo o boom regulador que tomou conta, a partir de 1998, do setor de saúde suplementar: em 2000, registraram-se 26 Medidas Provisórias, 21 Resoluções do Conselho de Saúde Suplementar, 18 Resoluções da ANS, com freqüentes contradições entre elas (Ramos, 2000); em setembro de 2002, vigia a 44a Medida Provisória, ou seja, aumentou o número de Medidas Provisórias editadas, da ordem de $70 \%$, em praticamente dois anos.

Esse caráter errático da ação reguladora do Estado, prevalente até então, poderia estar refletindo a ausência de uma linha clara acerca do papel do Estado na regulação de um mercado que apresenta especificidades marcantes. $\mathrm{Na}$ área de saúde, desde a década de 60, partindo de grandes expressões do pensamento econômico norte-americano (Arrow, 1963 apud Sicsu, 2000), admite-se a existência de "falhas de mercado", não como exceção, mas como regra. A principal falha, neste caso, diz respeito à heterogeneidade de informação entre os agentes econômicos envolvidos na relação de consumo entre médico e paciente. E, também, na impossibilidade de o paciente consumir serviços que não sejam legitimados, na maioria dos casos, por uma recomendação formal do prestador - que atua como agente do usuário. Outros aspectos enfatizados por Sicsu (2000) se referem às circunstâncias anormais que envolvem o consumidor quando de uma doença, que afetariam a racionalidade de suas decisões. Musgrove (1999) admite, também, que mercados competitivos de seguro apresentam as seguintes características: 
seleção de risco, seleção adversa e risco moral (moral hazard). Embora explicações mais detalhadas, calcadas na análise das principais correntes teóricas que têm orientado a regulação de mercados em saúde possam ser encontradas na tese (Andreazzi, 2002), é plausível supor que essas "falhas de mercado", supostamente passíveis de contorno através de uma regulação apropriada, possam ser características imanentes à própria existência desses mercados. Não duvidando da capacidade inovativa do modelo regulatório brasileiro em resolver esta questão, seria de um idealismo desmobilizador, ou uma prestidigitação, fazer crer que isto será uma tarefa fácil, quiçá, possível $^{25}$.

Afirmar, assim, que constitui avanço na eficiência, com preservação da qualidade, a reforma do Estado, que passa de financiador e prestador a regulador, é afirmação passível de discussão. As características dos mercados de saúde, como a especialização do conhecimento e a assimetria de informação justificariam esse questionamento. Para as firmas privadas, as características dos mercados supracitadas, aliadas à maior capacidade de governança, recomendariam fortemente maior integração da gestão, do financiamento e, inclusive, da prestação de serviços, dentro de sua estrutura (Hart, 1988). Sequer cogitar que, do mesmo modo, isso não possa ocorrer com as instituições públicas é, no mínimo, ideológico. É possível supor, tal como no livro patrocinado pelo Ministério da Saúde (Negri e Giovanni, 2001), que o objetivo principal desse tipo de reforma foi a contenção de despesas públicas, e não o aumento da eficiência do Estado ${ }^{26}$.

Uma regulação honesta de mercados competitivos de seguros privados de saúde sempre irá perseguir inovações, buscando modestamente coibir os abusos do poder econômico ${ }^{27}$, sobretudo numa perspectiva do Direito do Consumidor. No entanto, os consumidores ainda não se vêem protegidos pela regulação, o que tem ocorrido principalmente com os planos individuais de assistência à saúde. Há brechas na legislação que permitem reajustes diferenciados entre as faixas etárias, como também os agravos para condições de saúde preexistentes acabam sendo elevados, tornando proibitivos os prêmios. Além disso, as entidades de defesa dos consumidores tampouco têm creditado à ANS estatuto superior à Justiça comum, nas suas demandas com as seguradoras ("O governo recua" - Correio Brasiliense, 16/08/01).

O Judiciário tende a estender a todos os segurados, direitos a rigor permitidos apenas para os contratos realizados após a Lei n. 9.656/98, que regulamentou a assistência suplementar em saúde e que não são maioria, ainda. Essa diferenciação de regras entre planos ditos "antigos" e "novos", 
em relação à Lei, foi paradoxalmente admitida pelas próprias organizações de consumidores. $\mathrm{O}$ aumento correspondente de prêmios, conseqüente à adaptação dos contratos, tem sido o motivo do aparente recuo das organizações de defesa dos consumidores. Conflitos relacionados à cobertura dos planos constituíram, em 2001, o principal motivo de processo ético junto ao Conselho Regional de Medicina do Rio de Janeiro, atingindo a Diretoria Médica de Hospitais. Os principais motivos estiveram relacionados à burocratização dos procedimentos, que antecede a atenção às necessidades médicas, o que é uma ameaça de agravamento de quadros caracterizados por urgências médicas ("Erros assustam o CREMERJ" - Jornal Extra, 23/ 10/01, p. 14).

Aos problemas de seleção de risco, imanentes ao modelo de seguros privados de saúde competitivos, agregam-se os derivados da conjuntura econômica adversa, da demanda decrescente e da competição mais acirrada pela carteira dos concorrentes. As representações atuais de empresários do setor $^{28}$ ressaltam os constrangimentos financeiros ao desenvolvimento de seus negócios. E, também, dos burocratas da ANS (Folha de São Paulo, de 27/08/01, p. B9), que estão tendo acesso às contas de uma parcela do mercado, as operadoras de planos de saúde, apontam neste sentido. Empresas de medicina de grupo presumivelmente de pequeno e médio portes foram liquidadas em 2001 (www.ans.gov.br). Hospitais lucrativos de médio porte são fechados no Rio de Janeiro, em 2002, ou se encontram em situação de venda não-voluntária. Além disso, algumas instituições tradicionais de caráter filantrópico passam por sérias dificuldades financeiras, de acordo com entrevistas efetuadas com executivos do mercado.

Como toda crise, ela não é igual para todos. Há os que dela se beneficiam, e estes vislumbram ganhar mais parcelas do mercado (Luiz Roberto Silveira Pinto, da Samcil/SP, em A Crítica - AM, de 7/09/2001). A concentração do mercado, conseqüência das vantagens das grandes firmas no processo competitivo, se vê aqui potencializada, tanto pela crise, quanto por medidas saneadoras do mercado promovidas pela ANS, como a imposição de barreiras à entrada, na forma de capitais mínimos e reservas técnicas iniciais (Resolução da ANS/RDC 77, de 17/07/2001, em www.ans.gov.br). Num país já marcado pela desigualdade, acentuam-se as desigualdades entre os diferentes consumidores. Para os usuários de planos de saúde em dificuldade, em geral, os mais vulneráveis do mercado, dificuldades ocorreram para fazer valer seus direitos de consumo, no momento da utilização de serviços de saúde. No entanto, as tentativas e erros da regulação não ate- 
nuaram ainda o risco desigual da heterogênea demanda.

As saídas apontadas pelo Governo brasileiro para a crise, em 2001, receberam grande rejeição da sociedade, tendo que ser convertidas de Medida Provisória para Projeto de Lei, a ser votado no Congresso Nacional. As mudanças foram: a possibilidade de comercialização de planos sem livre escolha de prestadores, com triagem para o acesso a consultas em maiores níveis de complexidade da atenção à saúde; a possibilidade de comercialização de planos de saúde com coberturas limitadas e segmentação por patologias ou níveis de complexidade; a abolição de fiscalização das empresas pelos Conselhos de Ética Profissional; e a ampliação do número de faixas etárias em que aumentos seriam permitidos. Tais saídas, paradoxalmente, aumentam a vulnerabilidade do consumidor, o que contradiz o próprio objetivo inicial da Lei n. 9.656/98. Apesar da forte reação da sociedade - órgãos de defesa do consumidor, entidades médicas e de hospitais ("O governo recua" Correio Brasiliense, 16/08/01) - nada garante que as respostas contidas nesse projeto, no campo da continuidade do modelo atual da relação públicoprivada, não tenham sido apenas adiadas para uma conjuntura política mais favorável.

Impasses são colocados à sociedade:

a) mercados competitivos de seguros têm como pressuposto características prejudiciais aos consumidores, principalmente através da seleção de risco e do controle de sinistros, ou seja, da assistência à saúde em desacordo com os padrões mínimos, socialmente aceitáveis, de qualidade;

b) a concentração do mercado, embora seja a tendência em curso, além de não atenuar as características supracitadas, tem também suas contrapartidas. Por um lado facilitaria, operacionalmente, a aplicação de algumas medidas constantes da regulação do mercado, como a fiscalização das empresas. Mas, por outro, não atenuaria a desproteção do consumidor. Pois é quase consensual entre as diversas correntes da Economia Política e também verificável na prática, que a principal conseqüência da concentração do mercado é a perda de bem-estar que traz para a sociedade. Isto em função das possibilidades do estabelecimento dos preços muito acima do custo médio de produção (Hilferding, 1973), auferindo as firmas, em conseqüência, lucros sobrenormais.

Tudo isto leva a supor que a necessidade de mudanças nas relações público-privadas em saúde, no Brasil, seja um elemento da agenda setorial 
dos anos vindouros. E que as soluções que respeitem os interesses atuais das operadoras de planos e seguros de saúde tenderão a se chocar com amplos setores organizados da sociedade. Isso confirmaria indagações de autores clássicos da regulação, como Kahn (1988), acerca dos melhores arranjos institucionais que possam viabilizar o alcance de resultados, socialmente considerados ideais, como um dos objetivos fundamentais da relação Estado/mercado.

Se não estavam ainda maduras, na sociedade brasileira ao final dos anos 80 , as condições necessárias à discussão dos termos da relação públicoprivada que ultrapassassem a simples concessão de que a atenção à saúde fosse "livre à iniciativa privada", segundo a Constituição de 1988, hoje não parece ser o caso. As soluções propostas nos anos 80 já não são totalmente suficientes, em face da problemática atual. Pois a própria dinâmica excludente do modelo atual vai explicitando as contradições para os agentes das mudanças. Os elementos presentes na crise brasileira atual, entretanto, já estavam assentados nos Estados Unidos, desde pelo menos os anos 80, quando o aumento de custos e as dificuldades de cobertura do modelo prevalente, com base no financiamento privado da atenção à saúde, eram problemas nacionais, privilegiados na agenda do então candidato democrata Bill Clinton, em 1992. E onde a implantação e continuidade da segmentação da atenção à saúde, entre uma demanda pública, residual e outra privada, hegemônica, não se fizeram, historicamente, sem resistências de parcelas significativas do movimento social. E, ainda, onde a força do grande capital na manipulação da mídia e na influência sobre os processos eletivos tem mantido seus interesses preservados, a despeito das aspirações da população por mudanças, entre as quais a implantação de um seguro nacional de saúde, nos moldes canadenses (Sommers \& Sommers, 1961 apud Andreazzi, 1991; Navarro, 1989; Leyerle, 1994; Noronha e Ugá, 1995).

A gravidade do cenário e a falta de perspectivas de saída por parte das atuais elites políticas e empresariais brasileiras não devem ser subestimadas como fator indutor da consciência e da criatividade coletiva. Neste sentido, uma saída distinta do padrão atual teria grandes contradições com o mix público-privado da forma como se configura, atualmente, no Brasil, pelas seguintes razões:

a apropriação, pelo grande capital financeiro, do excedente financeiro destinado à saúde e à seguridade, de modo geral, é incompatível com as necessidades de financiamento da melhoria das condições de saúde do conjunto da população, sobretudo a mais vulnerável, mesmo que 
subsídios e renúncias fiscais sejam eliminados. Isso devolve a assistência suplementar mercantil a sua configuração mais tradicional de reembolso de despesas com atenção à saúde, de uma forma bem restrita, para as camadas, de fato, abastadas;

dificilmente seriam princípios organizativos de um sistema de saúde baseado nos interesses da população (e não em suas estratégias de sobrevivência) aspectos inerentes ao processo de acumulação dos seguros e serviços de saúde. Estes aspectos são: a seleção de risco, a seleção dos tratamentos mais lucrativos, o controle gerencial de prestadores de saúde baseado na concorrência e a direcionalidade da ciência e da técnica segundo interesses mercantis;

isso não implica que os prestadores privados, principalmente aqueles constituídos para a viabilização do trabalho dos médicos e outros profissionais de saúde, não tenham imenso papel na melhoria do atendimento à saúde da população, desde que a colaboração, e não a competição, seja o incentivo existente. Assim como certas características de amenidades da prestação de serviços, que não interfiram na eqüidade na qualidade técnica do atendimento, não possam se manter como direito de consumo. E, finalmente, que não se possa prever mecanismos de financiamento para tal, organizados de forma mutualista ou não-lucrativa.

\section{Referências Bibliográficas}

ALMEIDA, C. O mercado privado de serviços de saúde no Brasil: panorama atual e tendências na assistência suplementar. Brasília: IPEA, 1998 (Textos para Discussão, 599).

ANDREAZZI, M. F. S. O seguro saúde privado no Brasil. 1991. Dissertação (Mestrado em Saúde Pública) - Escola Nacional de Saúde Pública, Fundação Oswaldo Cruz.

ANDREAZZI, M. F. S. Teias e tramas: relações público-privadas no setor saúde brasileiro na década de 90. 2002. Tese (Doutorado em Saúde Coletiva) - Instituto de Medicina Social, Universidade do Estado do Rio de Janeiro, Rio de Janeiro.

BAHIA, L. Planos e Seguros Saúde: padrões e mudanças das relações entre o público e o privado no Brasil. 1999. Tese (Doutorado em Saúde Pública) - Escola Nacional de Saúde Pública, Fundação Oswaldo Cruz. 
BAHIA, L. Planos privados de saúde: luzes e sombras no debate setorial dos anos 90. Ciência e Saúde Coletiva, v. 6, n. 2, p. 329-339, 2001.

BANCO MUNDIAL. Relatório sobre o Desenvolvimento Mundial 1993. Rio de Janeiro: Fundação Getúlio Vargas, 1993.

BATISTA JR., P. N. O círculo de giz da globalização. Novos Estudos CEBRAP, v. 49, p. 84-97, nov. 1997.

BRAGA, J. M. C. Dimensões econômicas e sociais do mercado de assistência suplementar. Rio de Janeiro: Agência Nacional de Saúde Suplementar, 2001. Mimeografado.

BRAGA, J. M. C. Financeirização global: o padrão sistêmico de riqueza do capitalismo contemporâneo In: TAVARES, M. C.; FIORI, J. L. (Org.). Poder e dinheiro: uma economia política da globalização. Petrópolis: Vozes, 1998. BRASIL. MARE. Projeto Organizações Sociais. Brasília: Secretaria da Reforma do Estado, [19-]. Mimeografado.

BUCHANAN, J. The political economy of the Welfare State. Stockholm: The Industrial Institute for Economic and Social Research, 1988.

CATTA PRETA, H. Seguro-saúde no Merco-seguros. Cadernos de Seguros, v. 17, n. 85, p. 10-11, 1997.

CHESNAIS, F. (Coord.). A mundialização do capital. Rio de Janeiro: Xamã, 1996.

CHESNAIS, F. (Coord.). A mundialização financeira: gênese, custos e riscos. Rio de Janeiro: Xamã, 1998.

COHN, A. Mudanças econômicas e políticas de saúde no Brasil. In: LAURELL, A. C. (Org.). Estado e políticas sociais no neoliberalismo. São Paulo: Cortez, 1995.

CONFEDERAÇÃO DAS MISERICÓRDIAS DO BRASIL. Santas Casas da Misericórdia e Hospitais Filantrópicos. Cadernos da IX Conferência Nacional de Saúde. Brasília: Ministério da Saúde, 1992.

CORDEIRO, H. A. As empresas médicas. Rio de Janeiro: Graal, 1984.

COSTA, R. C. R. Descentralização, financiamento e regulação: a reforma do sistema de saúde no Brasil durante a década de 90. Rev. Sociol. Polit. Curitiba, v. 18, p. 7-19, 2002.

COTTA, R. M. M. Et al. A crise do SUS e a fuga para o mercado. Ciência e Saúde Coletiva, v. 3, n. 1, p. 94-105, 1998.

DAIN, S. Do Direito Social à Mercadoria. 2000. Tese ( Livre docência) - Instituto de Medicina Social, Universidade do Estado do Rio de Janeiro, Rio de Janeiro.

DAVIES, W.; LYONS, B. R. Concentration In: __. Economics of indus- 
trial organization. Survey in Economics. London: Longman, 1988. p. 73126.

DIAS, P. J. Elementos para la construcción de una estrategia frente al proceso de privatización de los servicios de salud en Venezuela. In: EIBENSCHUTZ, C. Política de saúde: o público e o privado. Rio de Janeiro: FIOCRUZ, 1995. p. 155-173.

DINIZ, E. Governabilidade, democracia e reforma do Estado: os desafios da construção de uma nova ordem no Brasil nos anos 90 In: DINIZ, E.; AZEVEDO, S. (Org.). Reforma do Estado e democracia no Brasil: dilemas e perspectivas. Brasília: UNB, 1997. p. 19-53.

DUPAS, G. Economia global e exclusão social: pobreza, emprego, estado e o futuro do capitalismo. São Paulo: Paz e Terra, 1999.

EVANS, P. O Estado como problema e solução. Lua Nova, v. 28/29, p. 107156, 1993.

FAVERET, A C. S. C. Et al. Estimativas do impacto da vinculação constitucional de recursos para a Saúde (Emenda Constitucional n. 29/2000) In:

. Gestão Municipal da Saúde. Brasília: Ministério da Saúde, 2001. p. 111-142. v.2

FAVERET, P.; OLIVEIRA, P. J. A Universalização excludente: reflexões sobre a tendência do sistema de saúde. Rio de Janeiro: IEI/UFRJ, 1989 (Textos para DIscussão, 216).

FIORI, J. L. Aos condenados da terra o ajuste fiscal. Rio de Janeiro. IMS/UERJ, 1996 (Série Estudos em Saúde Coletiva, 137).

GADREY, J. L'Économie des services. Paris: Éditions La Découverte, 1996.

GAZETA MERCANTIL. Panorama setorial - Seguros. São Paulo, 1996. GINZBERG, E. Tomorrow's hospital: a look to the twenty-first century. New Haven: Yale University Press, 1996.

GLADE, W. A complementaridade entre a reestruturação econômica e a reconstrução do Estado na América Latina In: BRESSER PEREIRA, L. C.; SPINK, J. Reforma do Estado e administração pública gerencial. Rio de Janeiro: Editora da FGV, 1998. p. 123-140.

HART, O D. Incomplete contracts and the theory of the firm. Journal of Law, Economics and Organization, v. 4, n. 1, p. 119-140, 1988.

HILFERDING, R. El Capital Financiero. Madrid: Editorial Tecnos, 1973. HIRST, P.; THOMPSON, G. Globalização em questão. A economia internacional e as possibilidades de governabilidade. Petrópolis: Vozes, 1998.

INSTITUTO NACIONAL DE GEOGRAFIA E ESTATÍSTICA. Acesso $e$ 
Utilização de Serviços de Saúde - 1998. Rio de Janeiro: IBGE, 2000. INSTITUTO NACIONAL DE GEOGRAFIA E ESTATÍSTICA. Departamento de População e Indicadores Sociais. Estatísticas da assistência médico-sanitária 1999. Rio de Janeiro: IBGE, 2000.

KAHN, A E. Indroduction: The rationale of regulation and the proper role of Economics. In: _. The Economics of regulation: principles and institutions. Cambridge: MIT Press, 1988. p. 1-19. v.1

KON, A. Economia Industrial. São Paulo: Nobel, 1994.

KORNIS,G. E. M. Entre o futuro do capitalismo e o capitalismo do futuro: a long and widing road. São Paulo em Perspectiva, v. 12, n. 2, p. 92-98, 1998.

LAURELL, A. C. La Logica de la Privatización en Salud. In: EIBENSCHUTZ, C. Política de saúde: o público e o privado. Rio de Janeiro: FIOCRUZ, 1995. p. 31-50.

LEOPOLDI, M. A. P. Os anos de incerteza: redemocratização, globalização financeira e desregulação do setor de seguros privados (1985-1993). In: ALBERTI, V. (Coord.). Entre a solidariedade e o risco: história do seguro privado no Brasil. Rio de Janeiro: Editora da Fundação Getúlio Vargas, 1998. p. 239-296.

LERDA, J. C. Globalização da economia e perda de autonomia das autoridades fiscais, bancárias e monetárias. In: BAUMANN, R. (Org.). O Brasil e a economia global. Rio de Janeiro: Campus, 1996.

LEYERLE, B. The private regulation of American Health Care. New York: M. E. Sharpe, 1994.

LOBATO, L. V. C. Reforma Sanitária e reorganização do sistema de serviços de saúde: efeitos sobre a cobertura e a utilização de serviços. 2000. Tese (Doutorado em Saúde Pública) - Escola Nacional de Saúde Pública, FIOCRUZ, Rio de Janeiro.

LOPES, L. T. A diferenciação de produto como vantagem competitiva. Dissertação (Mestrado em Administração) - Escola de Administração de Empresas da Fundação Getúlio Vargas, São Paulo, 1993.

MATTOSO, J. Produção e emprego: renascer das cinzas In: LESBAUPIN, I. O desmonte da Nação. Balanço do Governo FHC. Petrópolis: Vozes, 1999. p. 115-132.

MÉDICI, A. C. Incentivos governamentais ao setor privado no Brasil. Rio de Janeiro: ENCE/IBGE, 1989 (Relatórios Técnicos, n. 1/890).

MÉDICI, A. C. O setor privado prestador de serviços de saúde no Brasil: dimensão, estrutura e funcionamento. Rio de Janeiro: ENCE/IBGE, 1990 
(Relatórios Técnicos, n. 2/90).

MELLO, J. M. C. A contra-revolução liberal-conservadora e a tradição crítica latino-americana. Um prólogo em homenagem a Celso Furtado.In: TAVARES, M. C.; FIORI, J. L. (Org.). Poder e dinheiro: uma economia política da globalização. Petrópolis: Vozes, 1998.

MENDES, E. V. O sistema de serviços de saúde no Brasil. Belo Horizonte, 2000 Mimeografado.

MENDES, E. V. Uma Agenda para a Saúde. São Paulo: Hucitec, 1996. MESA-LAGO, C. Financiamiento de la atención a la salud en America Latina y el Caribe, com focalizacion en el seguro social. Washington, D.C.: Banco Mundial, 1989.

MONTONE, J. Regulação dos planos privados de assistência à saúde pela ANS: avaliação, perspectivas e interface SUS - Saúde Suplementar. Brasília. Disponível em : <http://www.ans.saude.gov.br>. Acesso em: 2001. MUSGROVE, P. Uma base conceitual para os papéis público e privado em saúde. In: ANDREAZZI, M. F. S.; TURA, L. F. R. Financiamento $e$ gestão do setor saúde: novos modelos. Rio de Janeiro: Editora Escola Anna Néry, 1999. p 63-103.

NAVARRO, V. Why some countries have National Health Insurance, others National Health Services and the United States has neither. Int. J. Health Services, v. 9, n. 3, p. 383-404, 1989.

NEGRI, B.; DI GIOVANNI, G. Brasil, radiografia da saúde. Campinas: Instituto de Economia/UNICAMP, 2001.

NORONHA, J. C.; UGÁ, M. O Sistema de Saúde dos EUA. In: BUSS, P.; LABRA, M. E. Sistemas de Saúde: continuidades e mudanças. Rio de Janeiro: Hucitec, 1995.

OCKÉ, C. O.; GAIGER, F. G.; ANDREAZZI, M. F. S. Avaliação dos gastos das famílias com assistência médica no Brasil: o caso dos planos de saúde. Rio de Janeiro: IPEA, 2002 (Textos para Discussão, 931).

OLIVEIRA, J. A. A.; TEIXEIRA, S. M. F. Medicina de Grupo: a medicina e a fábrica In: GUIMARÃES, R. (Org.). Saúde e Medicina no Brasil: contribuição para um debate. Rio de Janeiro: Graal, 1978. p. 181-205.

PEREIRA, L. Em busca de um novo perfil institucional do Estado: uma revisão crítica da literatura recente. $B I B$, n. 44, p. 81-103, 1977.

PINTO, E. Planos privados de saúde geram economia ao estado. Seguros e Riscos. São Paulo, v. 10, n. 94, p. 18-21, 1996.

PIOLA, S. F.; BIASOTO JR., G. Financiamento do SUS nos anos 90 In: NEGRI, B.; DI GIOVANNI, G. Brasil, radiografia da saúde. Campinas: 
UNICAMP, 2001. p. 219-232.

PIOLA, S. F.; RIBEIRO, J.A. C.; OCKÉ, C. O. Financiamento das políticas sociais: o caso do Ministério da Saúde. Revista do Serviço Público, v. 51, n. 3, p. 75-98, 2000.

POCHMANN, M. A década dos mitos. São Paulo: Contexto, 2001.

POSSAS, C. A. Epidemiologia e saúde. São Paulo: Hucitec, 1989.

RAMOS, L. F. R. Por dentro da lei: Medicina Social. Informe ABRAMGE.

São Paulo, ano 15, n. 167, p. 1-2, 2000.

RIBEIRO, J. M. Regulação e contratualização no setor saúde In: NEGRI, B.; DI GIOVANNI, G. Brasil, radiografia da saúde. Campinas: UNICAMP, 2001. p. 409-443.

ROCHA, P. No limiar do século XXI: globalização e saúde. 1997. Tese (Doutorado em Saúde Coletiva) - Instituto de Medicina Social, Universidade do Estado do Rio de Janeiro, Rio de Janeiro.

SALMON, J. W. A perspective on the corporate transformation of health care. Int. J. Health Services, v. 25, n. 1, p. 11-42, 1995.

SICSU, B. Seguro saúde nos Brasil dos 90: uma análise da competição. Rio de Janeiro: Universidade do Estado do Rio de Janeiro, Instituto de Medicina Social, 2000. Projeto de qualificação para doutorado.

SINGER, P. As raízes do desastre social: a política econômica de FHC. In: LESBAUPIN, I. O desmonte da Nação: balanço do governo FHC. Petrópolis: Vozes, 1999. p. 25-44.

SOLA, L. Estado, transformação econômica e democratização no Brasil. In: 1993. (Org.). Estado, mercado e democracia. Rio de Janeiro: Paz e Terra,

TAVARES, M. C. Da substituição de importações ao capitalismo financeiro. Rio de Janeiro: Zahar, 1972.

TAVARES, M. C.; FIORI, J. L. (Org.). Apresentação. In: Poder e dinheiro: uma economia política da globalização. Petrópolis: Vozes, 1998. TEIXEIRA, A. O ajuste impossivel: um estudo sobre a desestruturação da ordem econômica mundial e seu impacto sobre o Brasil. Rio de Janeiro: Editora da UFRJ. 


\section{NOTAS}

1 Médica, professora assistente do Departamento de Medicina Preventiva e do Núcleo de Estudos de Saúde Coletiva da Universidade Federal do Rio de Janeiro.

2 Economista, professor adjunto do Departamento de Planejamento e Administração em Saúde do IMS/UERJ, Pró-Cientista da Universidade do Estado do Rio de Janeiro.

$3 \mathrm{O}$ artigo em questão desenvolve e aprofunda as relações de cooperação intelectual entre dois pesquisadores, interessados em ampliar a produção de conhecimentos e o debate acadêmico com outros pesquisadores acerca das relações entre o público e o privado no campo da saúde.

4 E no tratamento homogêneo da relação entre Estado e mercado no setor saúde (Cohn, 1995).

5 O papel destinado ao financiamento público da saúde nessa década, entretanto, não está bem esclarecido. Se até 1994 não existem dúvidas de que sua redução foi expressiva, sua recuperação a partir daí tem sido objeto de polêmicas quanto à real possibilidade de enfrentar as necessidades da população, mesmo a parcela de recursos mais escassos. Assim, quanto ao gasto federal, trabalho da OPAS/Representação do Brasil, de 1998, apontou que, em 1996, o gasto encontrado, de 89 dólares per capita, seria menor do que o de 1989. Braga (2001) ressalta que, em 1994, ele teria representado 5,3\% do dispêndio efetivo do Governo federal, enquanto que, em 1998, caiu para 3,5\%. Estudos mostraram o desvio crescente de função de fontes federais do Ministério da Saúde para o pagamento de encargos previdenciários da União e dívidas (Piola, Ribeiro e Ocké, 2000). Quanto aos gastos de estados e municípios, as estimativas são que, de fato, tenham aumentado (Faveret et al., 2001), repercutindo num aumento do gasto público per capita com saúde, relativo a 1989, de US\$ 80 (Médici, 1994) para US\$ 152. Esses números, entretanto, são baixos para os padrões internacionais de países de renda média e para o padrão de gasto per capita estimado para os usuários de seguros privados de saúde brasileiros. Conforme a tabela 1, em 1999, o faturamento foi de US\$294. Com uma sinistralidade média em torno de $80 \%$, teríamos um gasto de US\$ 235 , somente para atenção curativa. No entanto, além da dificuldade razoável de se obter séries comparáveis de gasto com saúde desde a década de 70 , não se estabeleceu o real impacto da maxidesvalorização da moeda brasileira face ao dólar (1998), sobre os gastos públicos, dado o peso de itens importados na produção de serviços de saúde.

6 “(...) esse extraordinário poder econômico privado - das empresas produtivas e das organizações financeiras - se lança de maneira hostil contra as políticas nacionais de proteção social, de um lado; por outro, contra as políticas nacionais de preservação dos sistemas industriais voltados para o mercado interno, transformando os Estados Nacionais em reféns do Grande Capital (...)” (Mello, 1998, p. 20).

7 Termo utilizado pela escola da escolha pública (Buchanan, 1988) para designar a tendência inelutável dos burocratas do Estado de buscar sua própria renda e não o interesse público. $\mathrm{O}$ que o projeto da reforma do Estado, através das agências reguladoras não explica é por que elas não teriam inclusive mais independentes das contingências eleitorais e possibilidades de mudanças da correlação das forças políticas no poder, os mesmos incentivos. Também Evans (1993) aponta que são vistos comportamentos predadores no Estado desenvolvimentista como no Estado ajustado.

8 Não é objetivo deste trabalho deter-se a fundo nos mecanismos institucionais de regulação, mas espanta que o Conselho Nacional de Saúde, órgão máximo de controle social do Sistema de Saúde, através do qual se deve dar principalmente a prestação de contas de todo o Ministério, seja considerado membro do Conselho de Saúde Suplementar, quando este deveria estar sob 
o comando do primeiro.

9 Termo que, segundo o Webster's Third New International Dictionary, Vol 1 (G \& C Merrian, Co, 1976, p. 13), significaria: “(...) the quality or state of being accountable, liable or responsible $(. .$.$) ".$

10 As versões de 1987 e 1996 da POF, envolvendo as regiões metropolitanas brasileiras, abrangeram, em 1987, quase a metade da população urbana e, em 1996, pouco mais de um terço dela. Houve similitude nas categorias utilizadas, o que facilitou comparações intertemporais (Ocké, Gaiger e Andreazzi, 2002).

11 Esses dados, extraídos das próprias empresas ofertantes e de consultoras privadas, são, de modo geral, compartilhados pelos pesquisadores do tema, no Brasil, como Andreazzi (1991), Bahia (1991), Mendes (1996), Almeida (1998), Dain (2000) e Bahia (1999; 2001).

12 De 1968 a 1978 - dois períodos, na verdade, aqui se apresentam: o "milagre" (até 1973), caracterizado por altas taxas de crescimento do produto, impulsionado por reformas que atacaram o problema do financiamento das atividades produtivas; e o II PND (1974-1978), caracterizado por incertezas macroeconômicas que levaram a uma aceleração da dívida externa. Políticas de corte keynesiano refrearam os efeitos internos da crise econômica mundial instalada, postergando-a para o período seguinte.

De 1979 a 1983 - recessão econômica, e suas conseqüências sobre as políticas de emprego e os gastos da Previdência Social; aceleração inflacionária.

De 1984 a 1989 - também caracterizado por dois períodos: a recuperação econômica de 1984 a 1985, e o período seguinte da Nova República, em que a heterogeneidade na condução da política econômica resulta em período de grande crescimento do produto e controle da inflação (Plano Cruzado), seguido do seu intenso descontrole. Aumentam, nos últimos anos, a despeito dos desequilíbrios macroeconômicos, os gastos sociais do governo central e de saúde, em relação ao período anterior (Médici, 1994)

1990 a 1994 - caracterizado por outro forte período de recessão econômica, com descontrole inflacionário e ajustes fiscais do Estado e pela instauração de um novo modelo econômico caracterizado pela liberalização do mercado interno e privatizações de empresas produtivas

1995 a 1998/2001 - período da estabilização da inflação através do Plano Real, porém com medíocre crescimento do produto no seu início e recessão, ao final. Mantém-se e aprofundase o modelo econômico instaurado no período Collor anterior.

13 A Fundação SEADE, realizou, na década de 90, em São Paulo, três versões desta pesquisa, de base populacional, que incluiu, entre suas perguntas, a posse de seguros privados de saúde.

14 Há, no entanto, que se observar que na metodologia desta pesquisa, a condição de convênio do empregador apenas era aplicável quando este financiava o plano. Não enquadraria situações que o mercado denomina de plano de adesão, nas quais o empregador (ou uma entidade promotora) pode intermediar a relação com a firma seguradora, mas a contratação do seguro é voluntária para o empregado (ou associado), que banca, financeiramente, o plano de saúde. Tendo características mistas entre a forma particular e exclusivamente do empregador, seu custo, em geral, também é intermediário entre elas, assim como as coberturas e outros benefícios.

15 A inflação médica, ou seja, a variação do índice de preços da atenção médica privada, calculado pela Fundação Getúlio Vargas, entre 1994 e 1998, foi de 191,4\%, ao passo que o Índice Geral de Preços (IGP-FGV) foi de 166,14\% (Conjuntura Econômica, outubro de 2001). 
Maria de Fátima Siliansky de Andreazzi e George Edward Machado Kornis

16 Catta Preta (1997) estima uma sinistralidade média para o seguro saúde, no seu conjunto, de $81,5 \%$ mais elevada para a modalidade de autogestão.

17 Cristina Calmon: "Seguradoras desistem de pessoa física" (Valor Econômico, 15/10/01, p. C3). Larragoitti, presidente da Sul América, nesse artigo atribui o fato à legislação restritiva de aumento de preços por parte da ANS, para os planos individuais.

18 Um bom exemplo disto são alguns hospitais que, a partir de meados dos anos 90, aceitam convênios, como a Clínica São Vicente, no Rio de Janeiro e o Hospital Albert Einstein, em São Paulo.

19 Exemplo deste caso foi a compra de leitos hospitalares privados para alcançar suficiência de cobertura de UTI neonatal, com valores mais elevados do que a tabela referencial (SIH-SUS), por parte da Secretaria Estadual de Saúde do Rio de Janeiro, em 2000, como resposta urgente às pressões políticas do Ministério Público de atendimento à saúde da população ("Atendendo no limite", Jornal do CREMERJ, ano 14, n. 124, jan 2001, p. 3).

20 Confirmam, também, o papel atribuído por Dupas (1999) às pequenas e médias empresas no contexto da globalização: franquias, terceirizações e subcontratações, subordinadas às decisões estratégicas das transnacionais e integradas a suas cadeias produtivas

21 "Unimed diversifica atividades no Sul de Minas Gerais" (Gazeta Mercantil, 29/08/01, Editorial); "Unimed abre novo hospital" (Jornal do Commercio do Recife, 18/10/01); "Unimed oferece Centro de Exames" (O Liberal - PA, 8/11/01, p. 5).

22 Como o IFC - International Finance Corporation, braço do Banco Mundial que financia o setor privado (Gazeta Mercantil, 12/05/1999). Também referido em Costa (2002).

23 Como se pode ver em Médici (1990), quanto à existência de um empresariado "moderno" da medicina de grupo que, em contraposição aos donos de hospitais, não almejava viver às custas do seguro social. Mas podemos perceber que almeja disputar clientela com ele.

24 Isto foi visto em alguns embates da década de 90, como a aprovação da CPMF (Contribuição Provisória sobre as Movimentações Financeiras) e a Emenda Constitucional n. 29/00, que estabelece percentual fixo dos orçamentos públicos para a Saúde.

25 Ilustra a afirmação a seguinte passagem tomada da Folha de São Paulo, de 16/11/01: “(...) Seguradoras e operadoras de planos de saúde ainda desrespeitam a lei e não oferecem atendimento médico imediato e completo a portadores de doenças preexistentes ao contrato, como câncer, diabetes e Aids. Essa é a conclusão de uma pesquisa realizada em São Paulo com 28 planos e seguros entre novembro e dezembro de 2001. A maioria ou não oferecia os planos ou as mensalidades eram tão caras que impossibilitavam o acesso (...)".

26 “(...) Então, aqui aparece a realidade nua e crua - parte importante dos movimentos de reforma visa, sobretudo, a conter despesas numa área social, tal como preconiza a cultura da mercantilização e do desmanche das instâncias públicas e coletivas (...)" (Braga e Silva apud Negri e Giovanni, 2001, p. 34).

27 O abuso do poder econômico é creditado a Braga (2001)

$28 \mathrm{O}$ segmento segurador, por exemplo, refere uma queda na lucratividade ou mesmo prejuízos, no ano 2000: “(...) A Sul América Aetna, a maior no mercado (...) em volume de prêmios (R\$1,4 bilhão) (...) contabilizou um prejuízo de R\$ 12 milhões no primeiro semestre. A BrasilSaúde também teve resultado negativo de R\$ 7,3 milhões. Já a Bradesco Saúde teve um lucro de apenas R\$ 439,2 mil, considerado irrelevante pelo presidente (Cristina Calmon: "Seguradoras desistem de pessoa física" - Valor Econômico, 15/10/01, p. C3). 


\section{ABSTRACT}

Transformations and Challenges in Private Health Care in Brazil in the 1990s

This paper attempts to extract from the heterogeneity of the Brazilian private health care sector a qualitatively new characteristic of the 1990 s, as well as the challenges of the sector's new dynamics, especially in its relationship to the public sector. The article's introduction discusses what are considered essential elements for understanding the changes occurring in the health sector. It situates the challenges within the framework of the economic model adopted in Brazil in the 1990s, focusing on developments linked to the dictates of productive (and especially financial) globalization. The second and third sections present the principal changes in the private health care sector in relation to supply and demand and their interrelations. Finally, by way of epilogue, the article discusses some of the challenges arising in the relationship between suppliers and consumers of so-called supplementary health care, i.e., "à la National Health System”.

Keywords: Brazil; health reform - 1990-1999; private health care; private health insurance; public-private relations in health.

Recebido em: 08/11/2002.

Aprovado em: 22/01/2003. 